\title{
A PRÁTICA DOS ENVELOPES FREINETIANOS COM OS ESTUDANTES DA PÓS-GRADUAÇÃO EM EDUCAÇÃO
}

Marcio Bernardino Sirino(*)

\section{DA EDUCAÇÃO BÁSICA AO ENSINO SUPERIOR: UMA CONTEXTUALIZAÇÃO FREINETIANA}

No ano de 2016, finalizando o Mestrado em Educação na Universidade Federal do Estado do Rio de Janeiro (UNIRIO), passei num concurso público para a Prefeitura Municipal de São Gonçalo/RJ para atuar como professor dos Anos Iniciais do Ensino Fundamental.

Fui lotado num Centro Integrado de Educação Pública (CIEP) e direcionado para trabalhar com todas as turmas do $1^{\circ}$ segmento do Ensino Fundamental numa disciplina chamada "Estudo Dirigido”, uma vez que os alunos permaneciam em jornada de tempo integral e a escola tinha como objetivo promover uma educação integral aos estudantes.

Neste lócus tive a oportunidade de desenvolver a prática dos Envelopes Freinetianos com meus alunos e socializar essa experiência na 38 ${ }^{a}$ Reunião Nacional da Associação de PósGraduação e Pesquisas em Educação (ANPEd), realizada em São Luís (MA) ${ }^{1}$.

Este mesmo trabalho, revisto e ampliado, foi publicado no livro coletivo "Fora da Sala de Aula: o lugar da Pedagogia Social” ${ }^{2}$, organizado pelo Prof. Dr. Arthur Vianna Ferreira coordenador do Grupo de Estudos, Pesquisas e Extensão Fora da Sala de Aula, localizado na Universidade do Estado do Rio de Janeiro, campus São Gonçalo. Grupo este do qual sou pesquisador integrante, desde o início de 2016.

\footnotetext{
${ }^{(*)}$ Mestre em Educação pelo Programa de Pós-Graduação em Educação da Universidade Federal do Estado do Rio de Janeiro (PPGEdu - UNIRIO); Professor da Universidade Castelo Branco (UCB); Especialista em Alfabetização dos Estudantes das Classes Populares (UFF - Angra dos Reis); Pedagogo (UCB); Servidor Público da Prefeitura Municipal de Angra dos Reis (PMAR); Membro do Núcleo de Estudos - Tempos, Espaços e Educação Integral (NEEPHI UNIRIO) e Pesquisador Integrante do Projeto de Extensão, Estudos e Pesquisas Fora da Sala de Aula - UERJ/FFP. Email: pedagogomarcio@gmail.com.

${ }^{1}$ Pode-se conferir este trabalho intitulado “A Educação social desenvolvida na aula de "estudo dirigido” numa escola de educação integral e(m) tempo integral do município de São Gonçalo (RJ)” no link: <http://anais.anped.org.br/ sites/default/files/arquivos/trabalho_38anped_2017_GT13_552.pdf>.

${ }^{2}$ Cf. SIRINO, M. B. A Educação social desenvolvida na aula de estudo dirigido numa escola de educação integral e(m) tempo integral do município de São Gonçalo In: FERREIRA, Arthur Vianna. (Org.). Dentro ou fora da sala de aula? O lugar da Pedagogia Social. Curitiba: CRV, 2018, v.1, p. 219-233.
} 
E, embora tenha sido um tempo, relativamente curto, essa experiência trouxe significativas vivências e reflexões acerca do papel da educação e a função social da escola, nesta contemporaneidade, como se pode observar no destaque que se segue:

A experiência desenvolvida com os "Envelopes Freinetianos” veio a incorporar no CIEP 411 uma poética pedagógica diferenciada na qual os alunos tiveram novas possibilidades de aprendizagem a partir de um olhar afetivo (SIRINO, 2017, p. 11).

Percebam que esta dimensão afetiva, para além da cognitiva, foi a que se evidenciou criando uma nova lógica no cotidiano escolar deste CIEP. A experiência foi tão prazerosa que estabeleci em mim o compromisso de, aonde quer que eu fosse, levar essa prática mais democrática.

Momento este em que, já em 2018, não estando mais na Rede Municipal de Ensino de São Gonçalo/RJ, inscrevo-me para participar de um processo seletivo para Professor Auxiliar da Universidade Castelo Branco3 - que, curiosamente, foi a instituição onde cursei minha Graduação em Pedagogia.

Tendo passado pelo processo seletivo, no início deste ano, antes mesmo de iniciar com minhas turmas da Graduação, presencial e a distância, fui convidado para ministrar aos estudantes da Pós-Graduação em Educação a disciplina “Técnicas e Dinâmicas de Grupo”.

Convém destacar que tive alunos da Especialização Lato Sensu em Psicopedagogia Institucional e Clínica e, também, Especialização Lato Sensu em Gestão Escolar Integradora. Ao todo, por hora, dialoguei com 60 (sessenta) alunos.

Embora as duas Especializações venham a se constituir por demandas distintas frente a suas especificidades, percebi a necessidade de levar a prática dos “Envelopes Freinetianos” para a Docência no Ensino Superior - assim como pude fazer com a Educação Básica, uma vez que atuando dessa maneira poderia contribuir para uma formação mais qualitativa dos profissionais da educação, além de criar uma nova ‘dinâmica’ na Pós-Graduação ao ofertar momentos de produção de sentido(s) com uma das técnicas mais interessantes de Celéstin Freinet.

\footnotetext{
${ }^{33}$ A Universidade Castelo Branco, criada desde 1971 e atualmente mantida por Marcelo Gissoni tem, em sua missão, uma real preocupação com o educar - tendo clareza da capacidade de influência e de transformação que a instituição possui, principalmente, para a Zona Oeste do Rio de Janeiro - localidade em que se encontra inserida, a saber: Realengo.
} 


\section{POR UMA EDUCAÇÃO MAIS DEMOCRÁTICA: A IMPORTÂNCIA DE FREINET PARA A EDUCAÇÃO}

Célestin Freinet (1896-1866) nasceu na França e foi um dos educadores que mais marcou a escola fundamental de seu país neste século [...] Freinet afirmava a existência de uma dependência entre a escola e o meio social, de forma a concluir que não existia uma educação ideal, só uma educação de classes.

(GADOTTI, 1999, p. 179)

Criador da "Pedagogia do Trabalho", Freinet chamava de “Trabalho” na compreensão de que, por meio de suas 'técnicas' - que, por sua vez, utilizavam-se do trabalho manual, tinha-se a oportunidade de ofertar maior sentido histórico à prática pedagógica. Gadotti (1999) assinala que “a necessidade do trabalho seria necessidade orgânica de se utilizar o potencial de vida numa atividade ao mesmo tempo individual e coletiva” (p. 177).

A Pedagogia Freinet fundamenta-se em 4 (quatro) eixos, a saber: Cooperação; Comunicação; Documentação e Afetividade. Esses eixos, juntos, compreendem o ato de educar enquanto construção coletiva.

Para dar conta desta demanda - de construção coletiva - Freinet elaborou as "Invariantes Pedagógicas” que, segundo Sampaio (1989) se configuram como “princípios pedagógicos que não variam seja qual for o povo que os aplica”.

Dentre as tantas Invariantes Pedagógicas significativas, destacamos a $27^{\mathrm{a}}$ que afirma que “a democracia de amanhã prepara-se pela democracia na escola. Um regime autoritário na escola não seria capaz de formar cidadãos democratas” por considerarmos que os Envelopes Freinetianos na Pós-Graduação buscou efetivar esta premissa - do exercício da democracia.

Neste enredo, convém destacar que a Pedagogia Freinet é composta por muitas técnicas que se configuram como um conjunto de práticas que fundamentam o fazer pedagógico, tais quais, a partir de Sampaio (1989) listamos a seguir.

- Expressão livre;

- Roda de conversa;

- Conselho de cooperativa;

- Texto livre;

- Livro da vida;

- Cantos de atividades diversificadas;

- Imprensa na escola;

- Duplicadores (mimeógrafos, limógrafos, máquina de escrever, papel carbono, xérox, fax, impressora de computador); 
- Jornal escolar;

- Jornal mural;

- Jornal falado - na classe, no gravador, no rádio, no vídeo;

- Fichários para consulta ou auto-correção;

- Planos de trabalho (semanais e mensais);

- Palestras dos alunos;

- Avaliação formativa - os brevês;

- Biblioteca de classe;

- Aula das descobertas - a aula passeio;

- Estudo do meio (ecológico, social, cultural e político);

- Troca de saberes entre as crianças;

- Correspondência (interescolar e inter-professores) do correio à internet;

- Encontro dos correspondentes;

- Expressão livre - artes plásticas, dança, teatro, música, fotografia, vídeo, cd-room, moda;

- As exposições organizadas pelos alunos.

Dentre as muitas técnicas sinalizadas acima, destacamos 3 (três) que, diretamente, se alinham com o objetivo desse relato de experiência - a prática dos "Envelopes Freinetianos” na Docência do Ensino Superior, a saber: a Expressão Livre; o Texto Livre e o Livro da Vida.

Estas técnicas foram escolhidas, pois, nos “Envelopes Freinetianos”, os estudantes tinham um espaço para se colocarem sem reservas e avaliarem o trabalho desenvolvido ao longo das disciplinas da Pós-Graduação (a expressão livre), após esta reflexão, escreviam de maneira autônoma suas considerações (o texto livre) e, por fim, estes apontamentos modificavam a prática pedagógica desenvolvida em sala de aula e se desdobravam em diversas atividades - desenvolvidas e expostas no portfólio de cada turma (Livro da Vida) - obviamente, tudo realizado com muito diálogo e reflexão coletiva. Subsequentemente, o Livro da Vida era enviado à Coordenação da PósGraduação - como uma forma de socializar o trabalho desenvolvido e apresentar as demandas postas pelos estudantes e, desse modo, poder oportunizar uma devolutiva ao longo do processo formativo, uma vez que muitas questões inseridas nos "Envelopes Freinetianos” se alinhavam com a estrutura e organização do curso.

Neste contexto, embasados nos pressupostos de Célestin Freinet, e elaborados a partir da reflexão sobre suas técnicas, os 3 (três) envelopes dispostos na parede da sala de aula - Felicito, Proponho e Critico - se configuravam num espaço de escrita espontânea para os estudantes, de avaliação das atividades desenvolvidas nas aulas e, ainda, de construção de um sentimento de 
pertencimento do espaço universitário e de valorização do olhar do estudante, na medida em que os alunos entendiam que suas contribuições - inseridas nos envelopes - seriam lidas, refletidas e consideradas.

\section{Ilustração 1. Envelopes Freinetianos}

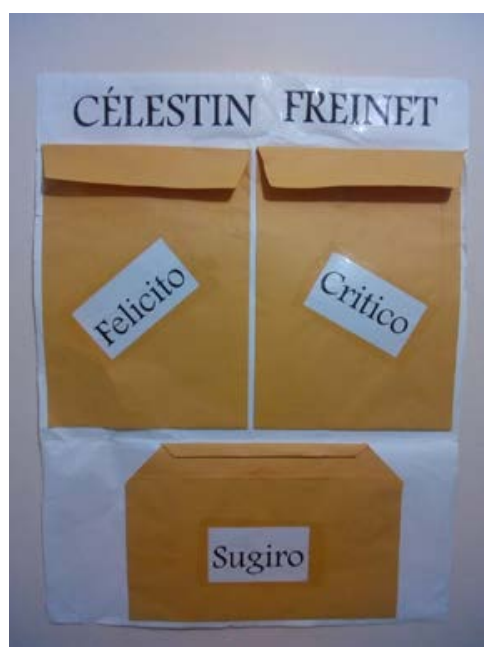

Fonte: Arquivos Pessoais do Professor (2018).

\section{FREINET NO ENSINO SUPERIOR: A CONSTRUÇÃO DE UM ESPAÇO DE PRODUÇÃO DE SENTIDO(S)}

Ao planejar as minhas aulas de “Técnicas e Dinâmicas de Grupo”, lendo, por acaso, a obra “Piaget, Vygotsky e Wallon: teorias psicogenéticas em discussão”, organizado por Yves de La Taille (1992), compreendi a diferença entre significado e sentido com a discussão que o mesmo trazia em sua obra.

O significado propriamente dito refere-se ao sistema de relações objetivas que se formou no processo de desenvolvimento da palavra, consistindo um núcleo relativamente estável de compreensão da palavra, compartilhado por todas as pessoas que a utilizam. O sentido, por sua vez, refere-se ao significado da palavra para cada indivíduo, composto por relações que dizem respeito ao contexto de uso da palavra e às vivências afetivas do indivíduo (OLIVEIRA, 1992, p. 81).

Exemplificando com a palavra “carro”, o autor abordava uma reflexão que embora esta palavra 'signifique', no geral, um veículo, de quatro portas, movido por combustível e utilizado para locomoção, se fosse perguntado a um adolescente o que o mesmo pensa sobre este vocábulo, automaticamente, ele responderia palavras como liberdade, festa, autonomia - dentre outros.

Diferentemente de um motorista, por exemplo, que ao ouvir a palavra “carro" associaria a trabalho, labuta, por vezes, stress etc. e, ainda, aprofunda a reflexão, trazendo a problematização de 
que se fosse perguntado a uma pessoa que atravessou a rua e, repentinamente, foi atropelada a resposta, certamente, seria outra - mais voltada para medo, traumas e quase morte.

Essa construção me possibilitou perceber a diferença de um significado e dos sentido(s) produzidos individualmente em cada sujeito do processo educativo. Percepção esta que me fez motivar-me a fazer de minhas aulas na Pós-Graduação em locais de produção de sentido(s) na perspectiva de contribuir para a formação mais completa dos estudantes e construir um espaço em que a aprendizagem viesse a ocorrer de forma mais democrática e significativa.

Neste contexto, logo no início da aula, os Envelopes Frenetianos foram postos na parede e a orientação ofertada aos alunos se pautou na liberdade que eles tivessem de - a qualquer momento do dia, visto que as aulas na Pós-graduação são aos sábados das 8h às 18h, quinzenalmente - inserir suas contribuições nos mesmos.

No que tange ao envelope "FELICITO", os estudantes tinham um espaço para darem os parabéns a alguma aula específica, atividade, dinâmica, fala apresentada ou mesmo sobre o sentimento obtido ao longo da aula.

Com relação ao envelope "PROPONHO” se configurava num campo de possibilidade para que os alunos dispusessem suas contribuições e sugestões para a aula, temas a serem abordados e, ainda, atividades a serem desenvolvidas.

Já referente ao envelope “CRITICO”, os alunos tinham a possibilidade de pontuar suas insatisfações com a tarefa desenvolvida, com a organização da turma ou, também, com os encaminhamentos ofertados - dentre um mar de possibilidades avaliativas - sempre numa perspectiva construtiva e mediadora, com Hoffmann (2014) nos bem sinaliza:

Numa perspectiva construtivista da avaliação, a questão da qualidade do ensino deve ser analisada em termos dos objetivos efetivamente perseguidos no sentido do desenvolvimento máximo possível dos alunos, de uma aprendizagem no seu sentido amplo, alcançada por eles a partir das oportunidades que o meio lhes oferece. Qualidade na concepção mediadora de avaliação é sinônimo de desenvolvimento máximo possível de cada um dos alunos. Visando a um permanente "vir a ser”, sem limites preestabelecidos, embora com objetivos claramente delineados e desencadeadores da ação educativa (p. 34 e 35).

Era muito interessante observar que, no meio de determinada reflexão, um aluno levantavase - livremente - sem pedir nem avisar e tinha a oportunidade de colocar suas impressões escritas 
nos envelopes na certeza de que esta sua avaliação seria levada em consideração e que teria um retorno.

Trabalhar com esta técnica da Pedagogia Freinet trouxe aos alunos da Pós-Graduação uma nova lógica de formação, como podemos perceber no depoimento de uma das alunas por meio de uma mensagem de e-mail.

Professor, confesso que não pude conter a emoção!

Me reporto ao passado, e lembro daquele meu colega tão calado, compenetrado, educado...

Me orgulho ao vê-lo hoje! Este professor tão competente, dedicado, motivador... que é você!

Fiquei feliz e emocionada revendo este caderno. Aprendi muito com você!

Foram maravilhosas estas duas aulas!

Deus te abençoe sempre!

Abraços!

Com carinho!!!

Sandra!!!!!

Este retorno tão significativo, reproduzido na íntegra, no recuo acima, revela o quanto as aulas de “Técnicas e Dinâmicas de Grupo” produziram múltiplos sentido(s) aos estudantes da PósGraduação.

Percebam que esta avaliação positiva das aulas se propagou, ainda, nas redes sociais quando outra aluna fez questão de registrar, publicamente, sua alegria com os encontros construídos coletivamente. 


\section{Ilustração 2. Agradecimento Público}

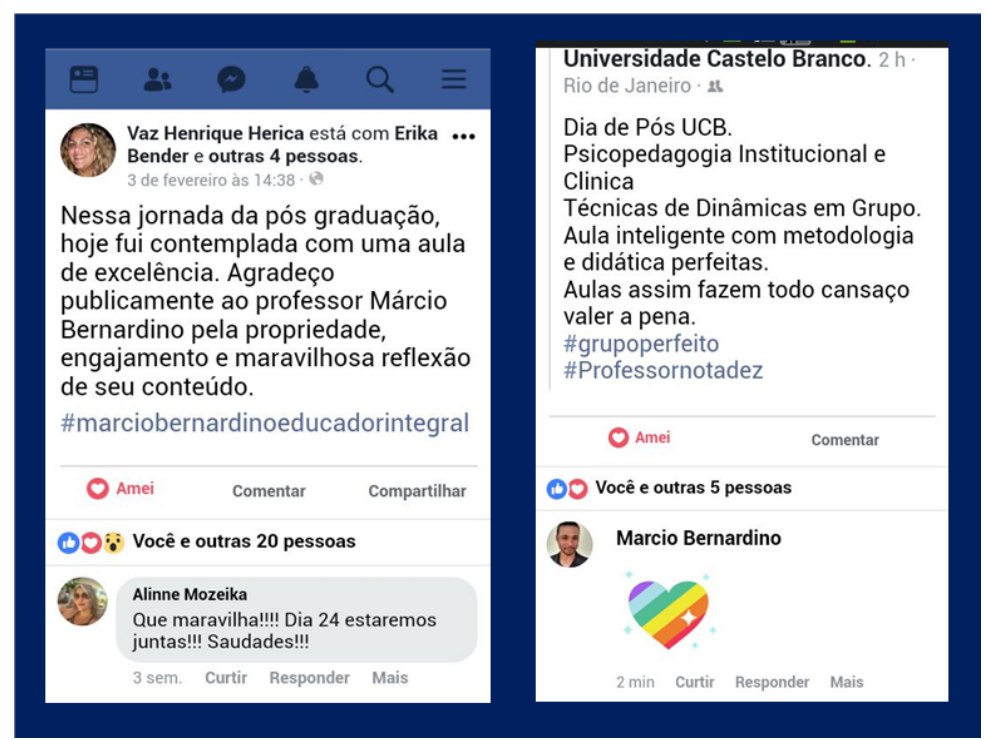

Fonte: Rede Social Facebook.

Frente a esta devolutiva tão significativa, senti necessidade de socializar esta prática educativa a fim de motivar outros profissionais a serem produtores de sentido(s) no cotidiano escolar da Educação Básica ou do Ensino Superior a fim de que possam modificar-se e, ao mesmo tempo, modificarem suas práticas, como nos sinaliza Scoz (2007) que "a partir da confluência entre o social e sua própria constituição subjetiva, o sujeito gera novos sentidos que vão modificando a si mesmo e às suas práticas” (p. 127).

Neste contexto, de produção de sentido(s) se evidencia a necessidade - por parte do educador - de uma escuta sensível sobre o processo educativo, em todos os segmentos da educação a fim de perceberem as demandas que emergem dos estudantes e, desse modo, poderem contribuir para a promoção de uma educação de qualidade, mais democrática, mais crítica e mais significativa, como a professora Hoffman (2014) compartilha.

Em 1992, René Barbier (Universidade 8, Paris) iniciou uma palestra dizendo que “conhecimento e experiência não são suficientes para se chegar à verdade!” Desenvolvendo uma tese sobre a "Escuta sensível em educação", ele fez-me refletir sobre certas posturas dos professores com as quais nos deparamos e a necessária sensibilidade dos supervisores e coordenadores de projetos para entendê-los em seus posicionamentos (p. 37 ).

Esse relato de Jussara Hoffman dialoga com a perspectiva desenvolvida nas aulas de “Técnicas e Dinâmicas de Grupo” - realizadas com os estudantes da Pós-Graduação em Educação 
da Universidade Castelo Branco, na medida em que para produzir esses múltiplos sentido(s), nas minhas aulas, usei de sensibilidade para democratizar as relações no cotidiano escolar, inseri os Envelopes Freinetianos para oportunizar um espaço de fala, de avaliação e de pertencimento e oportunizei momentos de diálogos e reflexões a todo momento.

Faz-se necessário evidenciar a importância desse movimento no ensino superior uma vez que, em geral, as especializações estão muito preocupadas com o repasse de conteúdos dispostos nas ementas de cada disciplina e pouco materializam ações concretas para que os estudantes se percebam sujeitos de seu processo educativo.

\section{FELICITO, CRÍTICO E SUGIRO: AS CONTRIBUIÇÕES DOS ESTUDANTES DA PÓS- GRADUAÇÃO}

Neste primeiro movimento, 60 (sessenta) alunos passaram pelas minhas aulas. Alunos de especializações específicas que se uniram ao estudar os pressupostos de Freinet e que perceberam, na oferta de um espaço democrático em sala de aula, a oportunidade de ter vez e de ter voz na universidade.

\section{Quadro 1. Síntese das Contribuições dos Estudantes (Turma 1)}

\begin{tabular}{|c|c|c|}
\hline FELICITO & CRITICO & SUGIRO \\
\hline $\begin{array}{c}\text { Metodologia; } \\
\text { Organização; Postura; } \\
\text { Reflexão; Pensamento } \\
\text { Crítico; Didática; } \\
\text { Dinâmicas; Dominio } \\
\text { do conhecimento; } \\
\text { Teoria x Prática; } \\
\text { Abertura para outras } \\
\text { compreensões; } \\
\text { Respeito à opinião do } \\
\text { outro. }\end{array}$ & $\begin{array}{c}\text { Nada; Sem críticas; } \\
\text { Poucos encontros; } 2 \\
\text { aulas; Tempo; Pouco } \\
\text { tempo para as } \\
\text { discussões; } \\
\text { Atraso/conversa fora } \\
\text { de hora; Textos não } \\
\text { disponibilizados } \\
\text { anteriormente. }\end{array}$ & $\begin{array}{l}\text { Continuar com a } \\
\text { prática pedagógica } \\
\text { com dinamismo; } \\
\text { Critérios para convite } \\
\text { de professores para a } \\
\text { Pós; Socialização por } \\
\text { e-mail ou por webcaf; } \\
\text { Reformulação da } \\
\text { carga horária; } \\
\text { Escrever um livro; } \\
\text { Mais disciplinas com } \\
\text { o Prof. Marcio. }\end{array}$ \\
\hline
\end{tabular}

Fonte: Elaboração do Professor (2018). 


\section{Quadro 2. Síntese das Contribuições dos Estudantes Turma 2)}

\begin{tabular}{|c|c|c|}
\hline & $\mathrm{CO}$ & 0 \\
\hline $\begin{array}{c}\text { Organização da } \\
\text { aula; Integração } \\
\text { oportunizada; } \\
\text { Manejo de turma; } \\
\text { Conhecimento; } \\
\text { Capacidade de } \\
\text { entender as } \\
\text { demandas e de } \\
\text { modificar-se para } \\
\text { abordá-las; Inserção } \\
\text { de Freinet e } \\
\text { Bauman; } \\
\text { Abordagem critica e } \\
\text { democrática; } \\
\text { Didática; Atuação } \\
\text { docente; Modo } \\
\text { carinhoso; }\end{array}$ & $\begin{array}{l}\text { Poderia haver mais } \\
\text { atividades } \\
\text { práticas; Nenhuma } \\
\text { critica; Carga } \\
\text { horária; Loja de } \\
\text { xérox não } \\
\text { funcionando; O ar } \\
\text { condicionado; } \\
\text { Mobiliário da sala } \\
\text { e recursos } \\
\text { fornecidos pela } \\
\text { Universidade; }\end{array}$ & $\begin{array}{c}\text { Nenhuma sugestão; } \\
\text { delimitar tempo para os } \\
\text { debates; Um tempo de } \\
\text { pausa entre as aulas para } \\
\text { descanso; Um espaço } \\
\text { reduzido com cadeiras } \\
\text { confortáveis; Curso todos } \\
\text { os sábados ao invés de } 15 \\
\text { em } 15 \text { dias; Que o } \\
\text { professor volte mais vezes; } \\
\text { Um quadro interativo } \\
\text { maior - melhorando as } \\
\text { visualizações dos textos; } \\
\text { Envio de material por e- } \\
\text { mail; Sugestões de leitura; } \\
\text { Trazer diferentes teóricos } \\
\text { da Educação; Atividade } \\
\text { fora da Sala de Aula. }\end{array}$ \\
\hline
\end{tabular}

Fonte: Elaboração do Professor (2018).

Os dois quadros encontram pontos que convergem em cada um dos Envelopes Freinetianos. Iniciando pelo envelope Felicito, quando os alunos parabenizam a Metodologia; Organização; Postura; Reflexão; Pensamento Crítico; Didática; Dinâmicas; Domínio do conhecimento; Teoria x Prática; Abertura para outras compreensões; Respeito à opinião do outro; Organização da aula; Integração oportunizada; Manejo de turma; Conhecimento; Capacidade de entender as demandas e de modificar-se para abordá-las; Inserção de Freinet e Bauman; Abordagem crítica e democrática; Didática; Atuação docente e o Modo carinhoso - estão dando pistas de que a aula cumpriu com o objetivo de produzir múltiplos sentido(s) e de tocar nas demandas que cada um possuía de forma a contribuir para sua formação mais completa.

Dando continuidade, numa perspectiva construtivista, foi oportunizado um espaço para as críticas. Muitos sinalizavam que nada tinham a criticar (Nada; Sem críticas; Nenhuma crítica), entretanto, outros destacavam a escassez no tempo para maiores aprofundamentos (Poucos encontros; 2 aulas; Tempo; Pouco tempo para as discussões). Outros, ainda, utilizaram do espaço para criticar os próprios colegas (Atraso/conversa fora de hora), assim como não deixaram de trazer contribuições significativas para melhor a organização da disciplina (Textos não disponibilizados anteriormente; Poderia haver mais atividades práticas) e o mais rico deste processo é quando as contribuições extrapolam à sala de aula com demandas para a Coordenação da Pós-Graduação dinamizar (Carga horária; Loja de xérox não funcionando; O ar condicionado; Mobiliário da sala e recursos fornecidos pela Universidade) - o que nos possibilita perceber que os alunos precisam de um espaço de fala para se colocarem, externalizarem suas insatisfações e se perceberem como sujeitos desse processo. 
Referente às sugestões, os estudantes trouxeram tanto o desejo de continuar com o professor pela forma como o mesmo conduz o trabalho (Continuar com a prática pedagógica com dinamismo; Escrever um livro; Mais disciplinas com o Prof. Marcio; Que o professor volte mais vezes) quanto apresentaram sugestões factíveis para a aula (Socialização por e-mail ou por Webcaf; delimitar tempo para os debates; Um tempo de pausa entre as aulas para descanso; Um quadro interativo maior - melhorando as visualizações dos textos; Envio de material por e-mail; Sugestões de leitura; Trazer diferentes teóricos da Educação; Atividade fora da Sala de Aula) e ainda, deram pistas à Coordenação de caminhos possíveis para melhorar na qualidade do serviço prestado (Critérios para convite de professores para a Pós; Reformulação da carga horária; Um espaço reduzido com cadeiras confortáveis; Curso todos os sábados ao invés de 15 em 15 dias) bem como houve aquele que nenhuma sugestão possuía (Nenhuma sugestão).

Contribuições que foram postas no "Livro da Vida” e encaminhada à Coordenação da PósGraduação na perspectiva de dar um retorno aos estudantes sobre as demandas sinalizadas nos Envelopes Freinetianos.

\section{Ilustração 3. Livro da Vida}

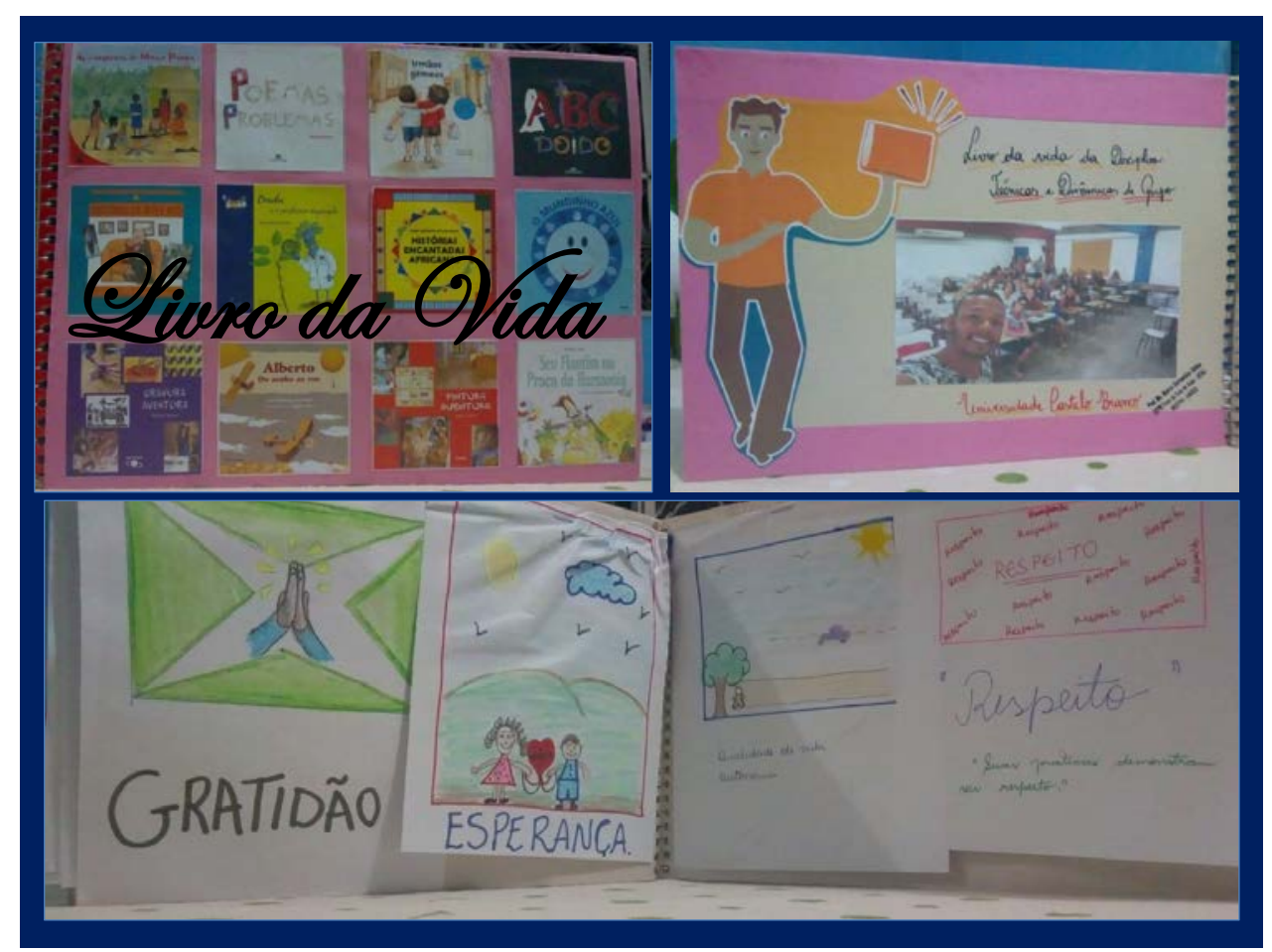

Fonte: Arquivos Pessoais do Professor (2018).

Percebam o quão rico se mostra este material uma vez que nele encontram-se inseridos os planejamentos das aulas, os slides utilizados em sala de aula, as atividades realizadas pelos alunos e, ainda, as contribuições inseridas nos Envelopes Freinetianos. 


\section{Ilustração 4. Livro da Vida (Parte 2)}

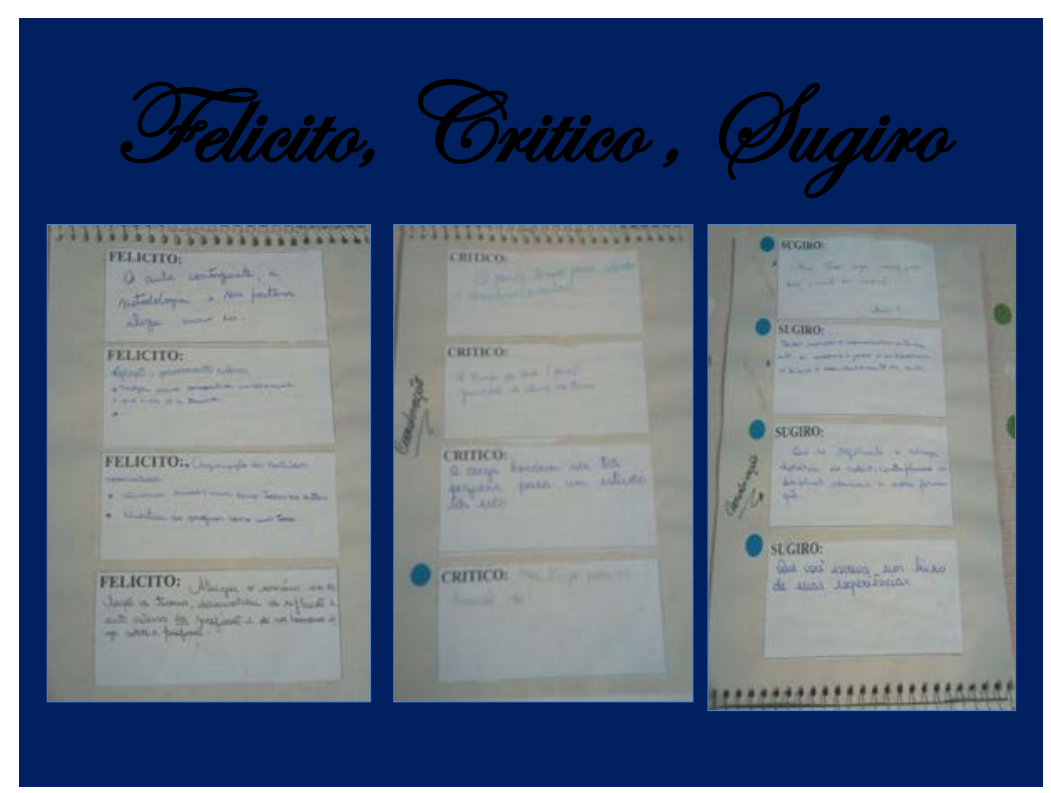

Fonte: Arquivos Pessoais do Professor (2018)

Material este que configura num portfólio das atividades, das discussões, das demandas e das questões dos estudantes e que foi repassado à Coordenação da Pós-Graduação na perspectiva de que uma devolutiva seja dada aos estudantes frente a suas solicitações.

Esse movimento foi tão rico tanto para mim, enquanto professor, quanto para os alunos enquanto sujeitos do processo de ensino-aprendizagem.

\section{CONSIDERAÇÕES FREINETIANAS}

Pode-se afirmar que as contribuições de Célestin Freinet para a Educação são grandiosas e que suas técnicas vêm ao encontro da possibilidade de oferecer uma educação de qualidade aos diferentes sujeitos do processo educativo.

Utilizar a Pedagogia Freinet é navegar na contramão de um ensino tradicional, técnico, fragmentado e descontextualizado - que não produz sentido(s) para os estudantes e, muito pelo contrário, associa o processo de ensino-aprendizagem à memorização; notas altas; obediência e passividade.

Sendo assim, na busca pela produção de múltiplos sentido(s) na Educação - em especial no Ensino Superior - acredita-se que a prática dos Envelopes Freinetianos tem condições de modificar o interior da sala de aula, promover espaços de interação, estabelecer uma nova 'dinâmica' sobre a aprendizagem dos estudantes e, ainda, favorecer a democratização das relações no cotidiano escolar. 
Neste desfecho, espero que a socialização desta experiência educativa, embasada nos pressupostos de Célestin Freinet, venha a produzir novos sentido(s) aos educadores e contribuir para a promoção de práticas mais democráticas em espaços escolares e não escolares - da Educação Básica ao Ensino Superior. 


\section{REFERÊNCIAS}

GADOTTI, Moacir. História das ideias pedagógicas. São Paulo: Ática, 1999.

LA TAILLE, Yves de. Piaget, Vygotsky, Wallon: teorias psicogenéticas em discussão. São Paulo: Summus, 1992.

OLIVEIRA, Inês Barbosa. (Org.). Narrativas: outros conhecimentos, outras formas de expressão. Petrópolis, RJ: DP et Alii. Rio de Janeiro: FAPERJ, 2010.

OLIVEIRA, Marta Kohl. O problema da afetividade em Vygotsky. In: LA TAILLE, Yves. Piaget, Vygotsky, Wallon: teorias psicogenéticas em discussão. São Paulo: Summus, 1992.

SAMPAIO, Rosa Maria Whitaker Ferreira. Freinet: evolução histórica e atualidades. São Paulo: Scipione, 1989.

SCOZ, Beatriz. Produção de sentidos, ensino e aprendizagem. Rev. Psicopedagogia, São Paulo, v. 24, ed. 74, p. 126134, 2007.

SIRINO, M. B. A educação social desenvolvida na aula de estudo dirigido numa escola de educação integral e(m) tempo integral do Município de São Gonçalo (RJ). In: REUNIÃO NACIONAL DA ANPED, 38. Anais das Reuniões Nacionais da ANPEd... São Luís: UFMT, 2017.

A educação social desenvolvida na aula de estudo dirigido numa escola de educação integral e(m) tempo integral do Município de São Gonçalo (RJ). In: FERREIRA, Arthur Vianna. (Org.). Dentro ou fora da sala de aula? $\mathbf{O}$ lugar da Pedagogia Social. 1. ed. Curitiba: CRV, 2018, v.1, p. 219-233. 


\section{RESUMO}

Este artigo visa socializar uma prática educativa desenvolvida com os estudantes da Pós-Graduação em Educação da Universidade Castelo Branco (UCB). Denominada "Envelopes Freinetianos", esta experiência se fundamenta nos pressupostos de Célestin Freinet e buscou oportunizar um espaço de democratização bem como de produção de sentido(s). Para esta finalidade, utiliza-se, da escrita narrativa - pela compreensão da necessidade de se evidenciar "outras formas de expressão" (OLIVEIRA, 2010) no processo de construção de conhecimentos e, ainda, de valorizar os múltiplos saberes desenvolvidos no chão da sala de aula. Como um achado significativo desse processo, pode-se afirmar a busca pela promoção de uma formação mais completa ao oportunizar espaços de livre expressão, discussão e reflexão.

Palavras-chave: Pedagogia Freinet; Produção de Sentido(s); Docência no Ensino Superior.

\section{THE PRACTICE OF FREINETIANOS ENVELOPES WITH POSTGRADUATE STUDENTS IN EDUCATION}

\section{ABSTRACT}

This article aims to socialize an educational practice developed with the students of the Post-Graduation in Education of the University Castelo Branco (UCB). Called "Envelopes Freinetianos", this experience is based on the assumptions of Célestin Freinet and sought to provide a space for democratization as well as the production of directions. For this purpose, narrative writing is used - through the understanding of the need to demonstrate "other forms of expression" (OLIVEIRA, 2010) in the process of building knowledge and also to value the multiple knowledge developed on the floor of the room of class. As a significant finding of this process, one can affirm the search for the promotion of a more complete formation by providing opportunities for free expression, discussion and reflection.

Key words: Freinet Pedagogy; Production of Directions; Teaching in Higher Education.

\section{LA PRÁCTICA DE LOS ENVELOPES FREINETIANOS CON LOS ESTUDIANTES DE LA POST-GRADUACIÓN EN EDUCACIÓN}

\section{RESUMEN}

Este artículo tiene como objetivo socializar una práctica educativa desarrollada con los estudiantes del Postgrado en Educación de la Universidad Castelo Branco (UCB). Denominada "Envelopes Freinetianos", esta experiencia se fundamenta en los presupuestos de Célestin Freinet y buscó oportunizar un espacio de democratización así como de producción de sentidos. Para este propósito, se utiliza, de la escritura narrativa por la comprensión de la necesidad de evidenciar "otras formas de expresión" (OLIVEIRA, 2010) en el proceso de construcción de conocimientos y, aún, de valorar los múltiples saberes desarrollados en el suelo de la sala de clase. Como un hallazgo significativo de ese proceso, se puede afirmar la búsqueda por la promoción de una formación más completa al oportunizar espacios de libre expresión, discusión y reflexión.

Palabras clave: Pedagogía Freinet; Producción de Sentidos; Docencia en la Enseñanza Superior. 